\title{
A case Study on Agile And Lean Project Management In Construction Industry
}

\author{
Ajendra Kashikar ${ }^{1}$ Devansh Mehta ${ }^{2}$ Bhawesh Motichandani ${ }^{3}$ Prof/Dr. Dasika \\ Chaitanya $^{4}$ \\ A Research Project submitted in partial fulfilment of the requirements for the degree of MBA (Tech.) \\ Under Supervision Year of Graduation - 2016
}

\section{Introduction}

While attending one of the gruelling nine hour lectures on Project Management, our visibly tired lecturer while initiating the topic of Lean Management caught my attention when he said and I quote "India is not a poor country, it's a poorly managed country". He mentioned that majority of projects in India get delayed by years and having interned at a government company for a big infra project which had already missed multiple deadlines I could definitely relate to it. He went on to explain the lean principles like elimination of wastes and its success in Japan, intrigued by the whole concept I asked him about its application in the construction industry. He said although it's been used overseas it still was at a nascent stage and had no evidence to support its usage in India. Drawn to the concept I decided to raise this with my father, who is a civil engineer with over 30 years of experience. I'm pretty sure I gave my father a shock when I asked him whether he uses lean management on his site. And he responded saying, "Haven't even heard about it son". It really puzzled me that despite being a core engineering sector the construction industry still uses old practices even though other sectors like manufacturing had evolved its practices to achieve efficiency in its operations.

Using internet as my primary tool for researching this topic and by taking help from a Professor with a masters in Construction management I came across several research papers which added more weight to the argument that Lean construction was beneficial to this industry and while going through one such paper I stumbled upon another concept called Agile Project management which though primarily used in the IT industry, if used alongside lean would lead to great increase in the efficiency and effectiveness of projects. There were many papers proposing this school of thought, although there was no practical evidence to back it.

This paper is an attempt to study whether project managers in the construction industry are aware of agile and lean project management techniques and its applications in the construction sector. We have measured the awareness levels of modern concepts like Agilean and LeaAgile which was proposed by Demur (2013) and Leagile, proposed by Owen, Koskela, Henrich, Codinhoto (2006). Our research is targeted towards builders and contractors who would ultimately be using these techniques as well as researchers and academicians who may find this paper helpful in convincing the builders/contractors for the benefits of these techniques. The real essence of this paper is to measure the awareness level of Lean and Agile Project management in the construction industry specific to the Mumbai environment. To add on, the opinions of industry experts show that these techniques will help increase the efficiency and effectiveness of projects which may also have high relevance in future.

\section{Present scenario}

The Indian Construction Industry lost its stream of growth drastically due to global financial turmoil. Lean construction and agile project management (APM), the two main representatives of recently emerging management philosophies, have been studied via this literature (Anwar, 2013) (Hass, 2007) (Salem O. S., 2006) and it is seen that these concepts are gradually accepted and implemented by the construction industry. Although their implementations have achieved great progress, difficulties and challenges are apparent. These two philosophies are both considering project complexity to a certain extent. However, none of them puts a main focus on interface issues as an integrated part of a project complexity. Actually some lean and agile applications increase project complexity to a great extent, such as complex relationships and intensive collaborations among small teams as well as constant changes. Interface Management (IM) (Chen, 2008) can be regarded as a facilitator when coping with project complexity. IM furthermore enables a smooth application for lean construction and APM. IM has been drawing more and more attention from both industry and academia in recent years Through managing and controlling boundary conditions among project entities, IM helps build a deep understanding of project complexity It is believed that IM benefits can greatly facilitate the further implementation of lean construction and APM in construction management.IM facilitate lean management by 2 theories: 1- last planner concept 2-transportation flow theory. To overcome the challenges faced IM makes use of work break down structure to eliminate the wastage and incorporate lean into construction industry. APM is 
managed by IM by 2 methods: 1-dynamic system development method 2-scrum and the challenges are overcome by proper communication, customer involvement, and proper coordination among various departments. As per literature reviewed (Chen, 2008), Future research will focus on specific strategies of incorporating IM within lean construction and APM techniques so that a standard IM can be applied across construction industry. The complexity or difficulty in supply systems that were put up by one of the literature are (Arbulu):

Scenario 1: utopia-when supply meets demand

Scenario 2: variable supply and reliable demand

Scenario 3: variable supply and demand

\section{Methodology adopted}

The case study is a qualitative research which is developed through interviews and by conducting nominal group technique with subject matter experts. The method of triangulation (narratives, Interview, nominal group) helped to get view of these concepts from all angles and get good insight into the present scenario. The need and output of this is mentioned in following sections:

\section{Need}

Success of any project or concept depends on need existing in market or tapping area that have been untouched in past. It has been observed that sometimes people are not aware about the need and when any such new concept is introduced, it automatically creates need in market. Same can be observed with agile and lean project management practices in construction industry. Various needs that call for use of agile and lean practices in civil industry can be stated such as the available resources are depleting at faster rate, therefore there is need to adopt agile and lean methods for construction. The dynamic environment of construction industry brings up the need to adopt agile and lean method. In the narratives which we took, two of our panellists mentioned that for every new project client needs are different and in our questionnaire respondents agreed that a lot of diversity is faced while accommodating customer needs. Also, within civil industry, couple of new industries and laws have been introduced such as labour law, safety law, quality law and forming department of same. There is high bureaucracy involved in present civil industry and because of these complex procedures there is high need for same. High dependency on traditional methods also calls for need of these methods (Robert Owen, 2006). In this era of internet and technology, fashion and glamour, luxury and leisure every client has its own needs. Today's customer demand high customisation and therefore using agile is becoming important as we all are aware about the complex activities involved in construction and these activities have very less efficient methods to be done. High NVA (non-value adding) activities in construction industry demand lean to be extensively used, as per average response of 3.9 out of $5^{2}$ from experts. Construction industry has seen massive change in technology and methodology. To compete with western construction industry, there is need to adopt these methods as experts also mark 3.9 out of $5^{3}$ for adoption of these techniques.

Also there is need to increase the speed of construction and efficiency of methods adopted, agile and lean needs to be incorporated in current methods used. Certain literatures have been written by foreign and Indian authors citing need for same. As per Everts, Piers, Najhus (2011) and Hass (2008) there is a need in to evolve from traditional project management as it is very rigid and disciplined and modern techniques need to be more flexible. Bertelsen (2008) has recommended using lean construction giving an example of lean manufacturing to suggest that lean construction would help reduce the cost of the entire project. Salem, Solomon have suggested that these techniques will help the medium sized firms to develop and compete against the bigger firms. Lean management techniques like last planner system and utopia will help in managing the supply system in large scale projects where the material used is in large quantities. Demur (2013) recommended using agile project management and also coined a new term called agilean to overcome the pressure faced by the civil industry in Mumbai and to tackle the complexities of the projects in a more dynamic way. Hanzed, Ballard and Tammelein (2012) suggested these techniques for improving the efficiency, effectiveness and reliability of lookahead planning.

\section{Hindrances experienced}

Although academicians and researchers have stated the advantages of Agile and Lean Project management in construction, they have not been able to demonstrate the benefits to the builders/ developers community and on the other hand Builders/ Developers community has not invested time and money to make the new philosophy successful. In the narratives which we took, Mr Sahajanand Kamat and Mr Vanvare, both extinguished professors mentioned that the biggest roadblock that these techniques are experiencing is the resistance to change. $85 \%$ of our respondents ${ }^{4}$ agreed that the construction industry has been using the standard practices for decades now and moving over to these new techniques will first need the acceptance and willingness of the people involved. This may sound easy but convincing people who have worked for years in 
this business to change their style of working is not a small thing. Dr Rastogi who was one of our respondents for the Nominal Group Technique and is a certified Lean management professional said that these techniques need the complete support of the top management not only for the support of these but also train the employees and convince them of its benefits. For these techniques to work there should be an honest effort from all the stakeholders to make it work. However in construction the partnerships between design and construction teams is not long term and as these techniques take time to implement, people don't usually go for it. Majority of construction industry is through unorganised sector. Making them understand the concepts of lean takes herculean task. Awareness of certified project managers is also less and thereby applying lean concepts requires concentrated effort which has just started and has miles to go. For these techniques to work it should be planned properly and in the construction in Mumbai there is major uncertainty on approvals, plan finalisation, techniques due to change in requirements and taste of customers or clients. Till the time the mind-set of contractors doesn't change these techniques won't see the light of the day in Mumbai.

In the current scenario, the Indian construction industry has to overcome many challenges, be it indirect or direct. Mr. V Balakrishna made a very interesting statement when he said and I quote, "India is not a poor country, it is a poorly managed country." Since the Indian construction industry is continuously facing with different phases of dynamic environment, it calls out for an urgent need to adapt concepts like Agile and Lean Project management.

One of the most crucial reasons of why it is taking substantial amount of time to implement Agile and Project Management concepts is the conventional mindset of the workforce. Most of the methods which are used in Indian Construction Industry involve techniques which have standardized procedures. This leads to formation of a conventional mindset and causes resistance to change. People are resistant to change because in a way it requires huge amount of investment and Time.

In addition to this, Indian construction Industry does not have workforce which is skillful and well trained. There is also lack of medium through which these workforces can be trained and updated about the concepts of Agile and Lean Project management. The Indian construction Industry involves many complicated bureaucracy procedures which increases the dependency levels in the construction industry. For example, a project cannot start unless the design which is proposed by an Architect is verified by a structural engineer, Client and Government. If any one of the entity is not able to verify on time, the project is bound to get delay. This is one of the most important problems of why it is hard to implement concepts like Agile and Lean project management.

The understanding of some of the advanced concepts such as Agilean and Leagile have not fully penetrated and absorbed in the Indian construction Industry. It is also found that the engagement level in not consistent amongst the stakeholders, Top management and Project Managers.

\section{Analysis}

The case study involves the use of a triangulation approach which consists of a survey, narratives and the nominal group technique for the analysis and thorough study of these problems. A survey was conducted by floating a questionnaire (Refer Appendix) to industry professionals who had worked in the construction industry and knew the integrities of it. A total of 30 responses were positively received. The respondents mostly included people who were civil engineers or architects and around 70\% of them had more than eleven years of experience. With the responses obtained, it was found that the current usage and awareness of lean and agile PM concepts are low. Less than $50 \%$ of project managers are aware about these concepts and less than that use these in real life. According to experts, there is very high need of such new project management concepts and can increase the efficiency as well as attract the present project managers. 4 out of 5 experts consulted for NGT said that they are attracted towards these concepts and Mr. Sanjay Kumbhar believes that this would increase the efficiency by $70 \%$. Also, concepts like agilean and leagile are centres of attraction and can help to bring revolutionary change in civil industry, 3 out of $5^{5}$ respondents favoured these club concepts.

It was found that more than $90 \%$ respondents favoured concept of lean and agile and consider it must in civil industry. Though engagement of stakeholders and top management to shift from traditional practices would be a challenge in itself as believed by 3 out of 5 respondents ${ }^{6}$ but considering ground realities, executives and project managers strongly favoured these concepts and paradigm shift. The Nominal group technique (NGT) approach is used for the purpose of understanding what the industry thinks about Agile and Lean Project management in construction. The nominal group technique (NGT) is a group process involving problem identification, solution generation, and decision making. It can be used in groups of many sizes, who want to make their decision quickly, as by a vote, but want everyone's opinions taken into account (as opposed to traditional voting, where only the largest group is considered). The method of tallying is the difference. First, every member of the group gives their view of the solution, with a short explanation. Then, duplicate solutions are eliminated from the list of all solutions, and the members proceed to rank the solutions, $1 \mathrm{st}, 2 \mathrm{nd}$, 3rd, 4th, and so on. The question asked to the experts was: 


\section{Maturity of agile and lean project management in the construction industry in Mumbai.}

Five responses were taken from the experts in this regard. The experts came up with their subjective views on the question above. The answers given were summarized and the main points were compiled and sent back to them where they were asked to rate these points between 1 to 5 . The experts overwhelmingly rated that the main hindrance behind the acceptance of these techniques was the unwillingness of the stakeholders in adopting something new and the lack of awareness was mostly attributed to the fact that the sector is highly unorganised with unskilled labour. All the experts have agreed that these techniques will help in reducing cost and reducing the time of projects. To add on furthermore, these techniques have high potential growth in the future in Mumbai.

In the final iteration we asked the experts to rank agile and lean management with respect to a maturity model. We have used a emergent collaboration maturity model. The purpose of the maturity model is to help organizations where they are today, where they should go in the future and the value of doing so, and how to get there. Organizations typically fall into one of five types of categories when it comes to collaboration in the enterprise. These are:

- The unaware organization

- The exploratory organization

- The defined organization

- The adoptive organization

- The adaptive organization

The experts came to a consensus that lean and agile are at the exploratory stage in the model. However everyone agreed that lean construction is more popular then agile project management. The experts mentioned the roadblocks as well as gave reasons as to why these techniques would be useful. One of the common points which came up was that the industry has been facing problems like cost over runs, project delays and poor quality of work. However changing times needs a change in approach. As mentioned by experts and something which we have come across in other research papers too, Agile Project management can be used in the design stage as it involves multiple iterations and as it embraces change as an opportunity for improved, early and sustained value delivery, it requires organisations to be more proactive than lean organisations. Whereas lean project management can be used in the execution stage as it focuses on reduction of non-value adding items which includes defects, excess inventory and unnecessary movement which can be found aplenty in the construction industry. These techniques will help project management \& execution teams to deliver the project 15 to $20 \%$ faster and these methods are perfectly suitable at team level \& help the challenges to integrate the Business and effective teams building. One more reason supporting lean was that it works best when the resources are minimum and the whole principle of lean is to work with minimum resources to provide maximum results. In current times, India has stepped up by focusing on its development agenda in the construction industry. India has been emphasizing on its Infrastructure development in order to become one of the fastest growing country in the world. However, in the path of advancement, the Indian construction industry has to overcome many challenges.

One of the methods which are used to evaluate the research study is Narrative inquiry. In this technique, the experts are subjected to share their experiences, stories, opinions and future aspects on the concept of Agile and Lean project management concepts. To add on, they also shared some of the crucial reasons or hindrances which are consuming substantial amount of time to adapt these advanced practices. It was found that 6 out of 8 think that Convectional Mind set of the Contractors/Project Managers will take substantial amount of time to adapt changes for implementing the concept of Agile. However, the application of these concepts can be used in designing stage specifically while using Business Information Model.

The survey conducted shows that $80 \%$ of the experts believe Lean Project management can be implemented in the future where the projects require customization. In addition to this, it can also be used for different functions like Supply chain, Human resources, Processes and Documentation. Similarly, Agile Project Management can be implemented in flexible and customized service operations which will help to make it more adaptive to the dynamic environment.

The implementation of the concepts like Agile and Lean Project Management should be done for achieving efficient and productive work procedures. By conducting seminars, workshops, expert talks and training will not only help in spreading awareness amongst the workforce but will also help in implementing Agile and Lean project management concepts in the construction industry. Most of the experts say, although the investment requirement for implementing these concepts is high, it will surely help in the long run by preventing the resources to deplete at a faster rate.

\section{Discussion questions:}

1. "India is not a poor country, it's a poorly managed country" (Vanvare, 2016). Elaborate on this with respect to the construction industry. 
2. How would you increase the acceptance level amongst the stakeholders with respect to these techniques?

\section{Questions for assignment:}

1. What are the major roadblocks for the acceptance and implementation of agile and lean project management techniques?

2. Why and where should agile and lean project management these techniques be applied and what is their relevance in future?

3. What is the awareness of agile and lean project management techniques with respect to the Emergent collaboration maturity model?

\section{Teaching Note}

With this paper we have tried to focus on the awareness of these techniques in the construction industry in Mumbai and have tried to understand the reasons behind the non-implementation of the same.

The basic objective of this research paper is to find the awareness of concepts like lean and agile project management among project managers or civil professionals working in the construction industry in Mumbai. And if people are aware we wanted to see the acceptance levels of these concepts. No new method is adopted easily if it doesn't yield significant increase in efficiency. This research paper shows the efforts made to check whether these concepts contribute to increase in efficiency. Efforts were made to know from the experts about acceptance of these concepts by stakeholders, shareholders and top management of the company. It's the normal human psychology to look at benefits and application of any new idea before accepting it and adopting it in his working. This research paper also includes checking Mumbai market with respect to requirement of these concepts and application of these concepts in current and future construction happening in city. We also tried to find out the awareness levels of modern concepts like Agilean and Leagile in the industry.

\section{Questions for assignment}

4. What are the major roadblocks for the acceptance and implementation of agile and lean project management techniques?

5. Why and where should agile and lean project management these techniques be applied and what is their relevance in future?

6. What is the awareness of agile and lean project management techniques with respect to the Emergent collaboration maturity model?

The Indian construction Industry is expected to emerge as one of the largest industry in the world by 2020 (Morgan, 2013). However, Indian construction industry faces major challenges in implementing advanced concepts like Agile and Lean Project management. According to the experts, the convectional mind set of the workforce stands out to be the major roadblock for causing hindrance in accepting Agile and Lean Project Management concepts. Many of the experts have also stated that due to absence of workshops and awareness programs related to these techniques, the labours working in Indian construction industry are not able to keep themselves updated which in the end boils done to resistance to change.

The Indian construction Industry majorly prefers to implement standardised techniques rather than implementing concepts like Agile and Lean Project Management. Experts believe, for implementing Agile and Lean Project management techniques more time is consumed and it requires huge amount of investment cost. For implementing these techniques, substantial amount of time will be consumed for shifting standardized practices to Agile and Lean Project Management. Detailed and precise training should be given to the workforce before implementing these concepts. This will result in increase in cost as well as consumption of time.

In addition to this, there are high dependency levels amongst the stakeholders of Indian construction Industry. It in a way makes the procedures and processes more complicated. Indian construction industry involves high bureaucracy levels amongst the top management which causes high uncertainty on approvals, documentations and governance areas. This boils down to one of the key roadblock in the preventing to accept Agile and Lean project Management techniques. The engagement level in not consistent amongst the stakeholders, Top management and Project Managers. The understanding of some of the advanced concepts such as Agilean and Leagile have not fully penetrated and absorbed in the Indian construction Industry.

The construction industry has been plagued with problems like project delays, cost over runs and poor quality for decades now. The industry is a lot more complex and dynamic now and there has been an increase in customer collaboration in the past decade. Around $77 \%$ of our respondents said that they face high diversity while accommodating individual customer needs. It is for these reasons that Agile and Lean project management techniques should be applied. Agile project management encourages customer collaboration and engagement and involves all the stakeholders. This helps counter the increasingly complex environment. Lean construction helps in reducing non value adding items and increases value for customers. It works with minimum resources and helps increase the efficiency and effectiveness of the project. As of now APM isn't 
being used in construction and lean construction is only restricted to off-site work and pre-fab construction. Lean construction is only been used in high end projects with cost sensitivity. Experts have recommended using APM in the design stage as it involves multiple iterations and takes many stakeholders into consideration, whereas lean can be used in the execution stage as it seeks to eliminate the seven wastes and improves the quality and reduces the costs and time for projects.

India is the fastest growing economy in the world and is trying to reposition itself from a highly bureaucratic country to a one where there is ease of business as it looks to position itself as a manufacturing hub of the world. To be a manufacturing hub there is a need to improve the infrastructure in the country and we need to do it fast. India has a long way to go in these techniques but has tremendous opportunities in terms big focus of government in Real Estate, Infrastructure, SMART Cities and Make In India. With 100\% FDI allowed, and MNCs entering in India, the way construction is done has to be changed dramatically. Lean and Digital Technologies can make it Agile, and give benefits in terms of Costs, Time, Quality and safety and sustainability. A very high percentage of our respondents agreed that standard practices are still used in the industry and around $70 \%$ agreed that we should move away from these and learn from foreign countries in this regard. Our respondents also agreed that the potential for these techniques is high in India and it will surely help project management \& execution teams to deliver the project 15 to $20 \%$ faster with lean, agile and team principles embedded into it. 3) What is the awareness of agile and lean project management techniques with respect to the Emergent collaboration maturity model?

A maturity model is a business tool used to assess an organization or process. The purpose of the maturity model is to help organizations where they are today, where they should go in the future and the value of doing so, and how to get there. Organizations typically fall into one of five types of categories when it comes to collaboration in the enterprise. These are:

- The unaware organization

- The exploratory organization

- The defined organization

- The adoptive organization

- The adaptive organization

Here is a simplified version of the maturity model:

\section{Emergent Collaboration Maturity Model}



When the collaborative capabilities of an organization increase, so does the business value that the organization will realize. Let's take a look at these 5 types of organizations in more details (much more comprehensive information and a grid is available in the book.

\section{The Unaware Organization}

Not surprisingly, unaware organizations are just that...unaware. Meaning, they are not really up to speed on what is happening around collaboration and the future of work; they just don't know what they don't know. Manager resistance is going to be strongest at this stage as value and business cases have not yet been established. There is also a high degree of uncertainty and fear as the organization tries to understand how 
emergent (or social) collaboration applies to the way it works. The opportunity and the upside for emergent collaboration here are great.

\section{The Value}

The value here is quite low, but the potential is the greatest.

\section{The Exploratory Organization}

At this stage organizations are spending more time researching and understanding what emergent collaboration is and how it can affect the business. In fact, organizations here may start defining what this means and what it can look like. Typically, organizations here start to see the possibilities of what can be done and begin to understand how emergent collaboration can solve business problems. We also start to see the formations of teams that are going to help drive this initiative within the organization. This is also where organizations will see most of their IT (and some manager) resistance. To move to the defined stage, there needs to be a very solid understanding of what emergent collaboration means to the organization and a strategic direction and vision has to start forming. Depending on the size of the organization, it can remain in this stage from one month to over three months.

\section{The Value}

The organization clearly sees where collaboration can benefit the enterprise. The strategic value gap begins closing as the capabilities for emergent collaboration start to increase. Teams begin forming that will be tackling this evolution of the organization. The key value here lies in knowing that things can be improved. The organization starts to get excited, and innovative ideas for collaboration begin flowing. The organization is now educated on emergent collaboration.

\section{The Defined Organization}

Here the organization needs to have a clearly defined strategy and direction for the emergent collaboration efforts. At this stage, the organization is getting ready to communicate and share the direction and vision and teams and roles are clearly defined. We also see use cases developed, measures of success defined, and potential technology solutions selected. To progress to the adoptive stage, organizations have to communicate their vision and direction for emergent collaboration and start implementing everything that was outlined and put together in the defined stage. The process of defining emergent collaboration for the organization can usually be completed in one to three months.

\section{The Value}

The strategic framework to make this happen is complete, and the organization is ready to begin implementing.

\section{The Adoptive Organization}

At this stage the organization is in the process of full implementation. Everything has been explored, teams have been established, the vision has been communicated, measures of success have been established, risks have been evaluated, and the road map and strategy have been developed. Organizations here can typically implement in one of four types of enterprise collaboration deployments. This is the stage of greatest learning for the organization as progress is evaluated and bench-marked and feedback is continuously collected. This stage can last from one to three years, depending on the size of the organization and how quickly things can get done. Employee resistance here is greatest as they try to embrace new strategies and technologies at work. The remainder of the emergent collaboration life cycle is spent in the adaptive stage.

\section{The Value}

The organization sees opportunities to engage and inspire employees and to retain and attract new talent by being perceived as innovative and cutting edge.

\section{The Adaptive Organization}

This adaptive stage isn't an end state; it's a continuous cycle of improvement and evolution. The adaptive organization has a very solid understanding of what works and what doesn't and is capable of making the right decisions. Organizations can easily regress into previous stages if, for example, they stop listening to and incorporating employee feedback into their efforts, which in turn can cause employees to abandon platforms. If employees don't feel supported and listened to, then chances are that adoption rates will never rise. The important thing here is that there are always going to be improvements, updates, changes to technologies, new best practices, new team members, new leaders, and evolved strategies. An adaptive organization is one that learns what works and what doesn't and is able to improve. 


\section{The Value}

This is where the organization sees the greatest business value from emergent collaboration as problems are solved and successes are repeated. Inefficiencies begin to be eliminated. Company morale increases as employees see that they have a voice and their feedback is being implemented. All necessary components for emergent collaboration are integrated, and sharing, finding, and collaborating on information are at their peak.

The experts came to a consensus that lean and agile are at the exploratory stage in the model. However everyone agreed that lean construction is more popular then agile project management. The experts claim that although the concept of lean agile project management was introduced in India in 2008 by ILCE its practice is at a very low level. The goals and objectives are defined to a small extent and fortunately though there is good focus on Safe working; others like sustainability, conservation of resources, elimination of wastes etc. is missing. With respect to culture though it's really lacking as there is no trust between partners and focus is more on contract rather than on sharing project risk and building trust. Although lean is being used in the industry many of its processes like waste elimination, last planner system, snags prediction and prevention are still not known to most. In terms of technology only ERP, Primavera and Doc Share, and sometimes BIM (Business Information Model) are used but back-end primarily. No technology for execution, where 85-90\% of manpower is engaged. While talking with respect to governance, due to the conventional mind-set, responsibility is not taken and there is hardly any focus on resolving the issues jointly, although the need for the same is recognized.

\section{Discussion questions:}

3. "India is not a poor country, it's a poorly managed country" (Vanvare, 2016). Elaborate on this with respect to the construction industry.

4. How would you increase the acceptance level amongst the stakeholders with respect to these techniques?

1)

India is considered one the richest countries in terms of their natural recourses but its poorly managed. Many experts think Indian construction industry is highly prone to project delays and cost escalation, one of the key reasons of making it prone to management problems is having bureaucratic structure. For Example, for approval of a proposed design by an Architect requires verification from the top management, Client, contractors and Government. Since many stakeholders are involved in approving decisions, the whole process gets more complicated and hard to manage.

The awareness of Agile and Lean Project management in construction industry is on the lower side which creates a huge barriers and gaps in accepting these advanced techniques. For example, at a given site in Mumbai it is not unusual to see many surplus amounts of inventories available at the site which leads to increase in non value adding items at the site.

In order to take utmost benefits from the resources which are natural there is the need of advanced technical concepts like Agile and Lean project Management amongst the people who are involved in resource exploitation and management. The technical education ensures that there is least amount of wastage of the resources. Hence, these concepts should be made compulsory amongst the people specifically involved in the areas of Indian construction Industry.

There has been poor picture of Indian Construction management image due to the persistent loopholes in policies and vision. Thus, the challenge of poor management needs to be paid attention in order to overcome the tremendous issues in Indian Construction industry.2)

We all are familiar with the fact that acceptance of any new method or concept requires nod from top management and satisfaction of all stakeholders. The techniques that we have discussed in this research paper are not new to Indian construction market but are not widely used. Here we have tried to find out the awareness level and inclination towards lean and agile project management concepts along with its application and various hindrances related to its acceptance. The one major roadblock or challenge that appears is acceptance of these techniques by various stakeholders related to construction industry. One way to convince them could be educating them about benefits of these techniques such as cost benefit, time benefit, having competitive edge over other players in market, making satisfactory products and so on. The waste in terms of plying of vehicles and labour and material and storing inventory and blocking money accounts to huge amount in this industry. Adopting lean techniques will help contractors to get rid of all these wastes that result in clogging of capital and utilize it for other purpose. Experts believe that such kind of waste is almost $20 \%$ of the total cost incurred which if saved can help in many ways. Also we see that there are many kinds of stakeholders involved related to each project and their demands vary drastically with each other to survive in market and sustain the name and satisfactory brand image, it's really very important for Project managers to accommodate needs of these stakeholders. Agile as a technique helps to accommodate all these varied demands with iterations that does not require re-structuring or re designing the whole project but the part related to concern stakeholder. Also club concepts like agilean and leagile helps in designing and executing the project efficiently, economically and 
effectively. Another way to convince the stakeholders could be by showing them the application of these concepts. These concepts are must when we talk about complex projects or huge infra projects. These techniques will definitely help in pulling more money from customers as they get products of their desire (using agile) and also from savings generated from cutting down various non-value adding activities in construction (using lean).

\section{Description of procedures:}

\section{Conclusion and summary}

The triangulation approach which we have conducted a survey, taken narratives from subject matter experts and conducted nominal group technique. For the survey, a questionnaire was floated and we received 30 responses and our respondents were all practitioners in the industry and 70\% of them have experience of over 11 years. Interviews were taken of eight experts for the narrative approach wherein we asked them to narrate their experience in the industry and the possible roadblocks for the non-implementation of Lean and Agile project management. NGT was conducted with five experts who shared their views on the maturity of these techniques in the industry and reached a consensus that these techniques are in the exploratory stage in India.

\section{Major Findings:}

- In the industry as a whole is still unaware of agile and lean project management techniques.

- Standard practices are still used by and large and there needs to be an attitudinal shift for the industry to evolve with the modern times.

- As per the Emergent Collaboration maturity model, these techniques are still in the exploratory stage that means the goals and process are being addressed but it hasn't been selected yet.

- With $100 \%$ FDI allowed, there is tremendous potential for these techniques in India, with Agile being used in the design stage and lean in the execution stage.

\section{Acknowledgements}

We would like to extend our sincere thanks to all those who contributed to our learning and helped us in the fulfilment of the paper. We would like to take this opportunity to thank our mentor Dr/Prof Dasika Chaitanya for her profound experience, guidance and support of this research. We would also like to thank Prof Sahajanand Kamat for his guidance and for being a part of the NGT panel. Mr Sanjay Kumbhar, Mr Bhawesh Thakkar, Dr Rastogi, Prof Avadhut Kshirsgar for being a part of the NGT panel. Everyone else who helped us with our survey and gave us interviews for the narrative approach.

\section{References}

[1]. Anwar, B. S. (2013). Agile approach in construction project management. India. . Bhatti group.

[2]. Arbulu, R. \&. (n.d.). Lean supply systems in construction industry. Lean supply systems in construction industry. Berkeley, USA.

[3]. Bertelsel, S. (2008). Bridging the gaps towards comprehensive understanding of lean construction. Copenhagen, denmark.

[4]. Chen, Q. R. (2008). Interface Management-A Facilitator Of Lean Construction And Agile Project Management. . P. 16.

[5]. Childerhouse, P. H.-M. (2007). Housing building supply chain.

[6]. Demur, S. (2013). Agilean pm-a unifying strategic framework to manage construction projects.

[7]. Hamzeh, F. B. (2011). Rethinking Lookahead Planning to Optimize Construction Workflow . Lean Construction Journal.

[8]. Hass, K. B. (2007). The Blending of Traditional and Agile Project Management.

[9]. Kamat, S. (2016). (Devansh Mehta. Ajendra kashikar, Interviewer)

[10]. Morgan, J. (2013). The Five step maturity model for building a collaborative organisation. Retrieved from the future organization.com: https://the future organization.com/five-step-collaborative-organization-maturity-model/

[11]. Panchal, D. (2016). (A. kashikar, Interviewer)

[12]. Paul everts, P. N. (2011). Towards agile project management and social innovation in construction industry. . Management and Innovation for a Sustainable Built Environment.

[13]. Robert Owen, L. K. (2006). Is agile project management applicable to construction? . Salford Centre for Research and Innovation .

[14]. Salem, O. S. (2005). Site Implementation and Assessment of Lean Construction Techniques. . Lean Construction.

[15]. Salem, O. S. (2006). Lean construction from theory to implementation.

[16]. Vanvare, M. (2016). (Devansh Mehta. Ajendra kashikar, Interviewer) 